\title{
THE GENITO-URINARY ASPECTS OF PROLONGED DECUBITUS
}

\author{
H. F. ANDERSon, F.R.C.S. \\ St. Georges Hospital, London
}

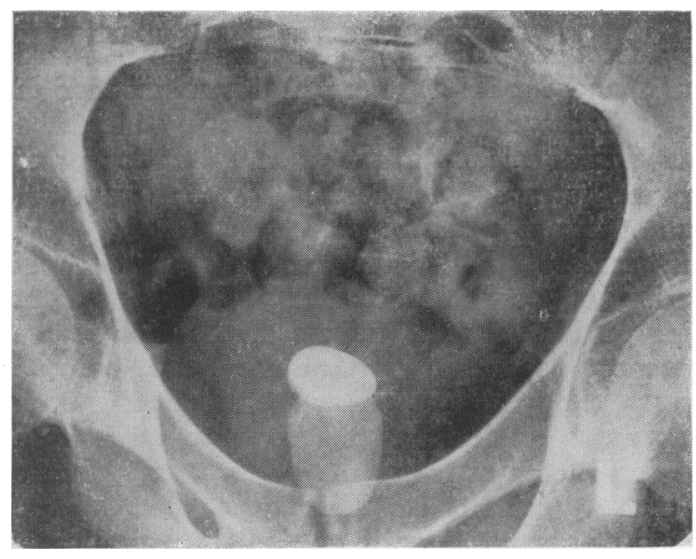

FIg. ra.-Vesical calculi due to infected urine after a cauda equina lesion.

On July I3, I95 I a healthy young man of 27 fell to the pavement from a height of $40 \mathrm{ft}$. He suffered multiple injuries, of which the most serious were crush fractures of several vertebrae in the lumbo-dorsal area, and an associated partial cauda equina lesion. $\mathrm{He}$ was unable to pass urine, so intermittent catheterisation was employed for a few days followed by tidal drainage through an indwelling catheter.

Recovery of the cauda equina lesion was rapid, and after 16 days the tidal drainage apparatus was taken down and voluntary micturition reestablished. There remained, however, a constant residual urine of $8 \mathrm{oz}$., and this, combined with a severe urethritis caused by the indwelling catheter, led to a chronic bacillus coli urinary infection which was resistant to all the available antibiotics. This infection persisted throughout his stay in hospital, for the first ten weeks of which

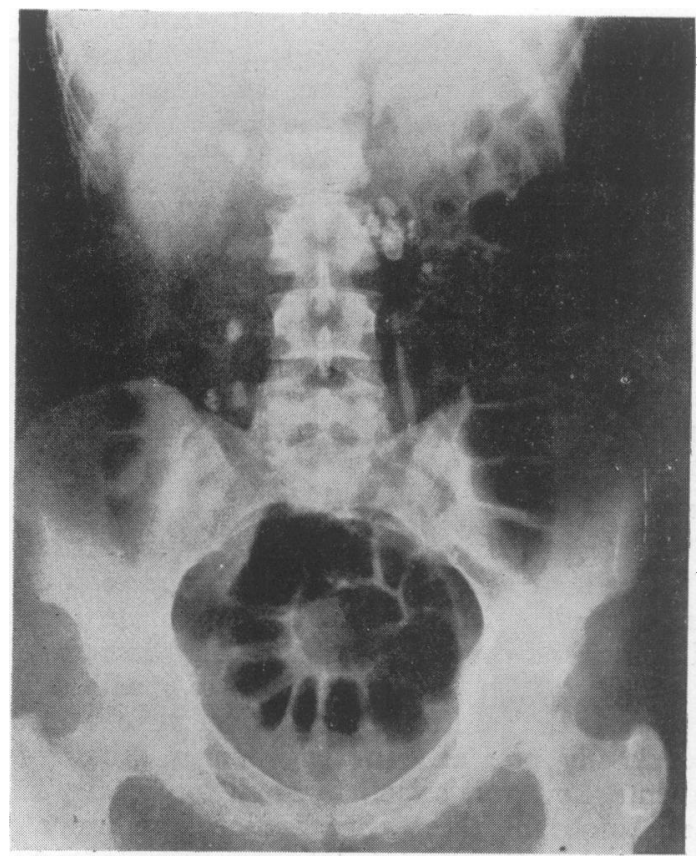

FIG. Ib.-Decubitus calculi in the kidney and ureter of a woman aged 35, five months after a severe attack of poliomyelitis.

he was wholly recumbent on account of his skeletal injuries.

After his discharge the urinary infection was controlled by terramycin, but it had recurred within a month. No treatment had much effect, and on May 2, 1952, ten months after his injury, an intravenous pyelogram was performed as his symptoms were getting worse. The X-ray (Fig. I) revealed two large stones in the bladder, and it was not until after these were removed at operation that the urinary infection finally subsided. 
This patient's record illustrates the three most important genito-urinary complications of prolonged decubitus. They are difficulty with micturition, urinary infection, and calculus formation. In the management of such patients attention must, therefore, be directed towards the prevention of these complications, and towards their treatment when they occur. The greatest effort should be made to prevent their occurrence, and it is with the problem of their prevention that this paper is mainly concerned.

There are many causes of prolonged decubitus, but the majority of patients fall into one of two groups. In the first group the genito-urinary system is normal, in the second it is abnormal. The first group comprises children and young adults suffering from chronic diseases, accidents, and affections of the skeletal system. The second group comprises, for the most part, older patients with bladder neck obstruction and chronic urinary infection, and includes those bedridden by age and cerebral thrombosis; it also includes, however, younger patients who, through injury or disease, have lost control of micturition. In the first group the prevention of urinary calculus is the paramount consideration. This applies equally to the second group, but in addition the treatment of retention, incontinence and established infection have to be considered.

\section{Patients with normal urinary tracts Decubitus Calculus}

\section{Aetiology}

The most striking genito-urinary complication of recumbent patients is their tendency to form renal calculi. In the older group of patients with urinary symptoms certain well known factors in the formation of calculi, such as renal back pressure, stasis, infection and an alkaline urine, are already present. In the younger group of patients, however, calculi form all too readily in the absence of these complications, and .much research has been devoted to this phenomenon.

The essential feature is a change in calcium metabolism. Calcium is mobilized from the bones, the blood calcium rises and the urinary excretion of calcium increases. Calcium ions are normally held in supersaturated solution in the urine, and any increase in the calcium concentration produces conditions in which precipitation, and consequent stone formation, is more likely to occur. If in addition stasis and infection are present, resulting in an alkaline urine which favours the precipitation of the calcium and phosphate ions already present, the chances of calculus formation are much increased.

According to Stevenson (1952), recumbency in tuberculous patients has an injurious influence on the metabolism of calcium and nitrogen, of which one of the effects is an increased $\frac{1}{\alpha}$ excretion of calcium. That osteoporosis occurs as a result of disuse and recumbency is well known. Histologically this is a true osteoporosis, the bony trabeculae becoming thin (Sissons, 1952). Physiologically there is an imbalance of osteoblast and osteoclast activity; bone formation decreases but bone resorption continues normally (Albright and Reifenstein, 1948). Biochemically, there is an increase in the blood calcium up to $12.6 \mathrm{mg}$. per cent., and a consequent increase in the urine calcium. Deitrick et al. (I945) immobilized four normal young men in plaster of Paris casts for six weeks and found calcium losses over the period of immobilization of 9 to $24 \mathrm{~g}$. (In this connection it should be noted, perhaps, that McCuskey (I950) reported an average blood calcium of 13.8 mg. per cent. during the first five days in ambulatory fracture patients.) According to Howard (1945) and Swartz et al. (1950), immobilization in bed is followed within a few days by increased excretion of calcium in the urine. The danger of calculus formation is therefore present from the earliest days of recumbency.

There are other factors concerned in the formation of decubitus calculus. In the patieng $\vec{\theta}$ lying on his back the calyces of the kidneys are the most dependent part of the renal drainage system, the pelvis lies below the ureter, and even the upper part of the ureter slopes upwards from the renal fossa as far as the pelvic brim. There is thus a tendency for urine to stagnate by the action of gravity alone in the pelvi-calyceal area. In the upright position, only the lower group of calyces lie below the outlet of the renal pelvis, and it is interesting to observe that it is in this dependent situation that most renal stones in all types of patient occur.

Infection predisposes to stone formation in two ways. In the first place, groups of bacteria and epithelial debris may form a nucleus around which crystalloids are precipitated. In the second place, if the infecting organisms are urea 'splitters,' a highly alkaline urine results which leads to precipitation of calcium salts. The aetiological factors concerned in the formation of decubitus calculi may be summarized thus:

I. Hypercalcinuria.

2. Stasis.

3. Infection.

4. Alkalinity.

\section{Prophylaxis}

From what has already been written it follows that one of the fundamental considerations in the care of recumbent patients is the prevention of renal calculi. There is no one panacea, just as 

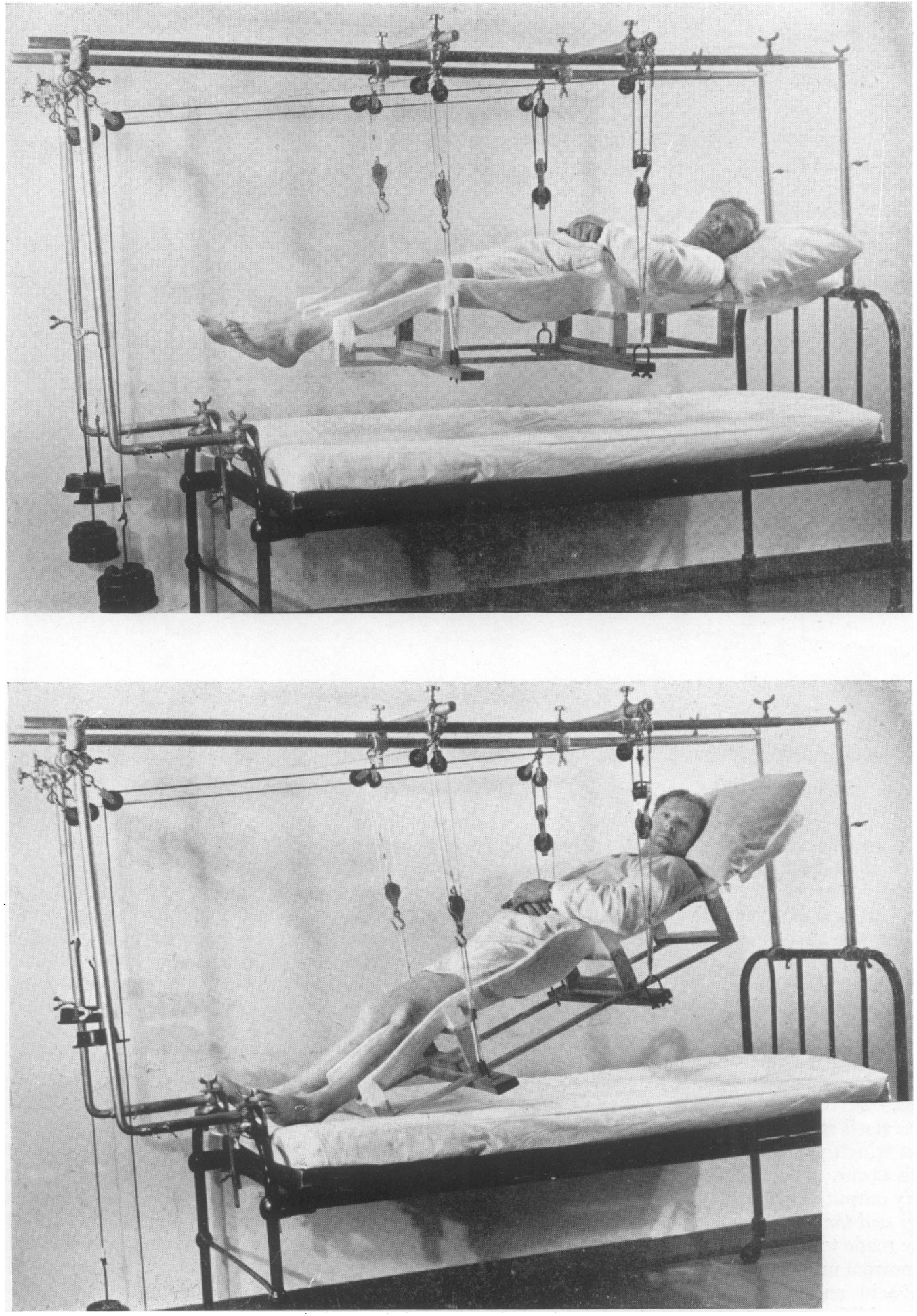

Fic. 2a.-The movable pulley bed designed by Hoskins and Nangle. 


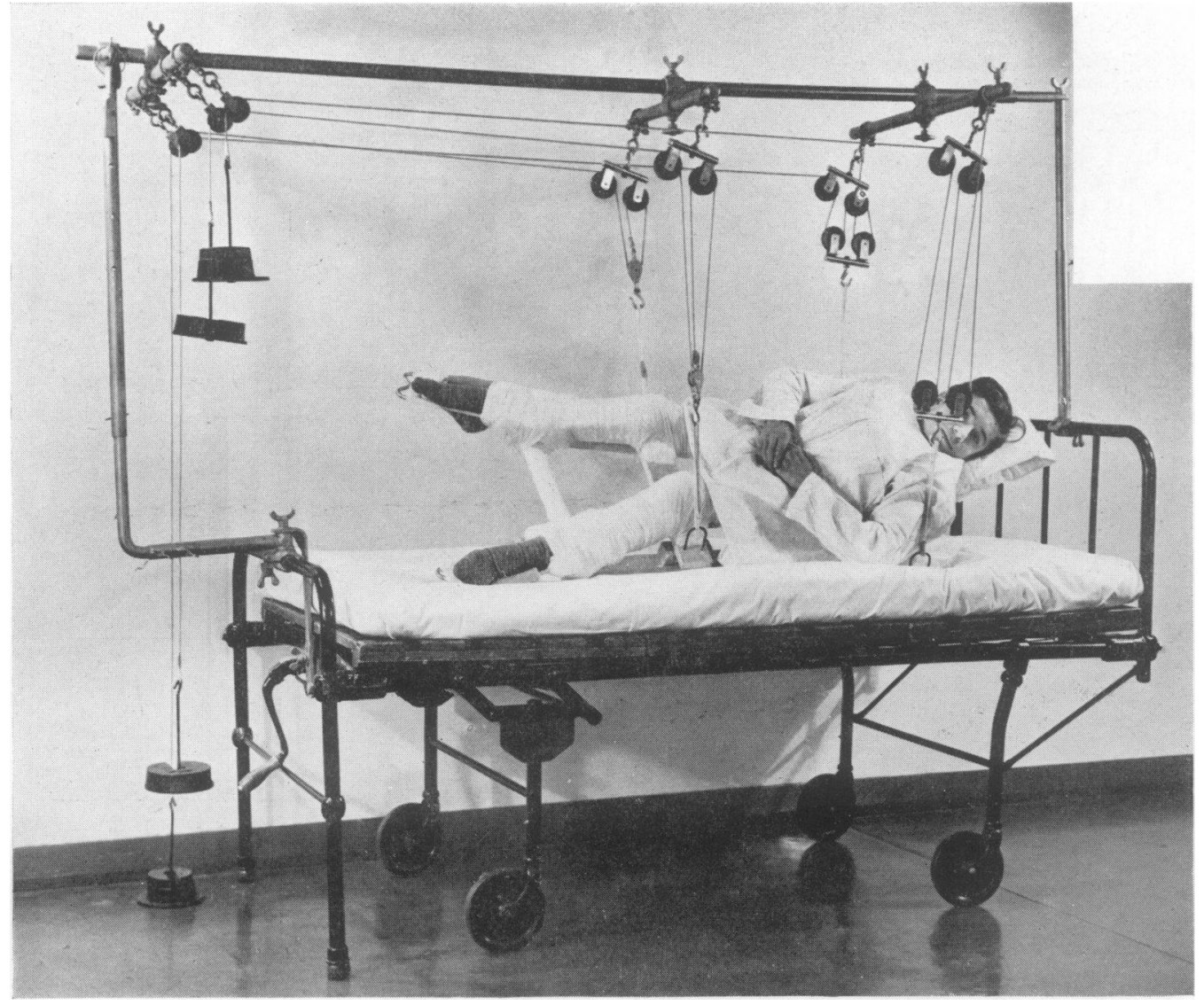

FIG. 2b.-To show lateral tilt of the Hoskins, Nangle bed.

there is no one cause, but careful attention to a number of medical, nursing and dietetic measures will usually prevent the formation of a calculus.

Diet. An acid ash diet with high vitamin $\mathrm{A}$ and B content, which contains a large proportion of meat, fish and cereals is advocated by many authorities (Joelson, I945; Kimbrough et al., 1950; Swartz et al., 1950). The purpose of this diet is to maintain urinary acidity, but according to Howard (1945) it has no effect on the excretion of calcium in the urine.

Fluids. A high fluid intake is essential. It prevents stasis in the kidneys and provides a dilute urine in which precipitation of crystalloids is less likely to occur. A daily intake of $4,000 \mathrm{ml}$. and a urinary output of 2,000 ml. should be maintained.

Drugs and the Control of Infection. Every effort must be made to keep the urine acid. In a patient with a normal urinary tract the urine will probably remain acid and the routine administration of urinary acidifiers is not necessary. At the first sign of alkalinity, however, urinary acidifiers must be administered to try and change the $p \mathrm{H}$ of the urine. Acid sodium phosphate may be given over long periods, though acidification is difficult if the infecting organisms are urea 'splitters.' Furthermore, in patients with impaired renal function, there is a danger of acidosis (Shorr et al., 1950). Infection is attacked along usual lines with the sulphonamides, streptomycin and chloramphenicol.

Posture. It has already been explained how recumbency in the supine position may lead to stasis in the renal pelvis and ureter. To overcome this difficulty the advantages of nursing the patient in the prone position have been stressed by Dick (1952); first, the calyces drain better; second, the patient, especially if paraplegic, exercises his arms more. A third advantage, according to Craig and Barr (1947), is that recumbency hypercalcinuria is less if active use of the arms and shoulders is maintained.

Prone nursing may not always be feasible or desirable, however. Frequent changing of the 


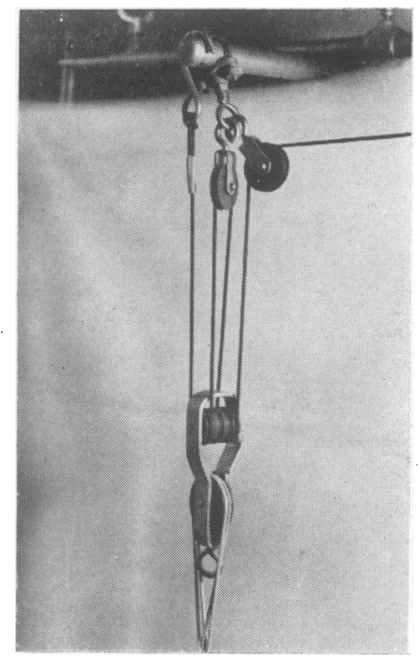

FIG. 3.-Details of pulley used in Hoskins, Nangle bed.

patient's posture is nevertheless most important. In this direction Hoskins and Nangle (195I) have made a notable advance with their movable pulley bed (Figs. 2 and 3 ). The frame or plaster shell in which the patient is immobilized is suspended over a pulley and counterweight system from beams erected over his bed. By pulling on the cords patients soon learn how to move themselves, and during the day they remain suspended and moving themselves about. At night the pulleys are unhooked and the frame allowed to remain on the bed.

Urinalysis. It is well recognized that the presenting symptom of renal calculus is often haematuria. This not uncommonly follows unusual movement or manipulation, such as lumbar puncture or a visit to the X-ray department. An even earlier sign, however, is the presence of red blood cells in the urine. These will only be discovered by microscopical examination and, therefore, every recumbent patient should have his urine routinely analyzed at fairly frequent intervals. Haematuria or the presence of red cells in the urine call for an immediate search for calculi.

Radiology. A 'silent' stone will only be discovered by X-ray examination. Straight X-ray examination of the kidneys should, therefore, be made at monthly intervals, supplemented by pyelography where necessary.

Reduction of Phosphate Absorption. If the amount of phosphate in the urine can be reduced, the tendency to form stones is correspondingly lessened. This can be achieved by administering by mouth aluminium hydroxide. This substance combines with the phosphorus in the bowel to form aluminium phosphate. Aluminium phosphate is an insoluble salt which is not absorbed by the bowel and is excreted in the stools. This leads to a fall in the inorganic serum phosphate and consequently a fall in the urinary phosphate.

Normal phosphate excretion is two-thirds of the intake. Of the I g. of phosphorus taken daily in an average diet, $600 \mathrm{mg}$. are excreted in the urine. This can be reduced to $100 \mathrm{mg}$. by the administration of aluminium salts. The patient remains in positive phosphorus balance, and calcium metabolism is but little altered; there is a slight increase in the urinary calcium, but this is much less than the fall in phosphorus. The alkali reserve is unaffected.

Aluminium is best administered in the form of gels, either as the hydroxide (aludrox) or the carbonate. Dosage is high; 90 to $200 \mathrm{ml}$., or 40 tablets, are required daily (Shorr et al., 1950). This high dosage, which is not very palatable, must be continued for the duration of recumbency, even though this be for years. The regime may cause constipation, nausea and distaste, but there are no serious complications. It must be controlled by monthly determination of the 24 -hour phosphorus excretion. Shorr et al. also maintain their patients on a constant diet containing $\mathrm{r}, 300$ $\mathrm{mg}$. of phosphorus and $700 \mathrm{mg}$. of calcium.

Satterthwaite (1947) has reported some convincing results of this treatment in paraplegics. In a control series of ro6 patients, 60 ( 56.6 per cent.) developed vesical and 18 ( 17 per cent.) renal stones. In a second series of 43 patients treated by aluminium gels and postural drainage, one developed vesical and none renal stones.

Hyalurodinase. Butt et al. (quoted by the Lancet, 1953) have recently shown that hyalurodinase may have some effect in controlling and preventing stone formation. The subcutaneous injection of hyalurodinase mixed with isotonic saline made turhid urines containing sediment much clearer. It was suggested that hyalurodinase increases the colloid content of the urine and that this in turn prevents crystal formation and growth. Clinically the method requires daily injections and control by complicated biochemical estimations, but success in the prevention of stones in habitual 'stone formers' has been reported. Further work will determine whether there is a place for hyalurodinase in the routine of stone prevention.

\section{Treatment}

On the whole, surgical removal is the most satisfactory treatment of a stone, followed by rigorous efforts to prevent recurrence. Providing it is not causing irreparable harm to the kidney, however, some surgeons prefer to leave the stone for the duration of recumbency, arguing that as 

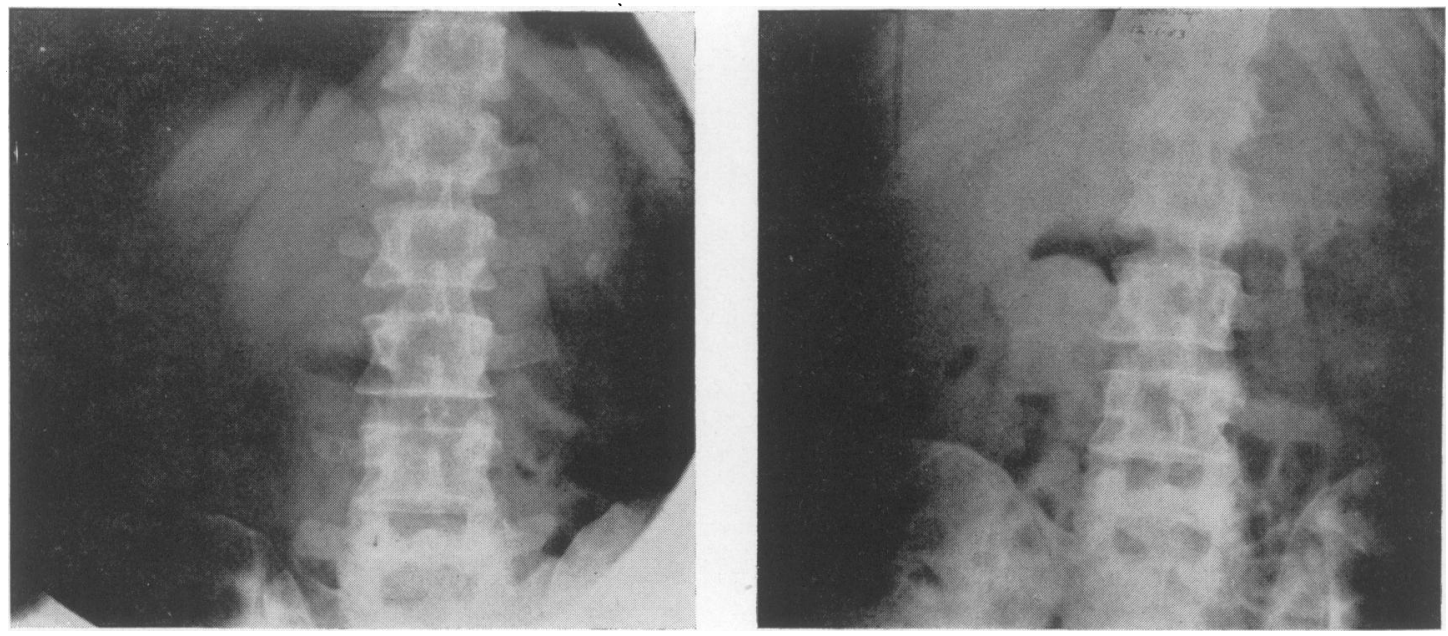

FIG. 4.- Small stones little more than a radio-opaque sludge dispersed by forcing a copious fluid intake.

long as stone-forming conditions persist recurrence is almost inevitable after removal. Certainly small stones confined to the calyceal system may be watched, and if they do not enlarge be left alone. Attempts have been made to dissolve small stones by irrigating the pelvis of the kidney through a ureteric catheter with solution $G$, but this method has not been successful (Riches, 1943). On the other hand, small stones, detected by routine radiography when they are probably little more than a radio-opaque 'sludge,' may be dispersed by mechanically washing them out of the calyces by forcing a copious fluid intake (Stevenson, 1953). The stones shown in Fig. 4 were washed away in this manner.

\section{Patients with Abnormal Urinary Tracts}

Recumbent patients with pre-existing or concomitant urinary disease are treated according to general principles, especially with regard to the urinary infection which is nearly always present in such patients. Three problems, however, require special consideration, though in practice they often overlap. They are :

I. Retention due to disorders of the nervous control of micturition.

2. Retention due to prostatic obstruction.

3. Senility.

\section{Disorders of Nervous Control}

Paralysis of the bladder is most often encountered as the result of injury to the spinal cord with paraplegia. Such injuries occur as the result of civil accidents and in war from gunshot wounds, and less frequently as complications of spinal tumours and thrombosis, disseminated sclerosis, $\vec{c}$

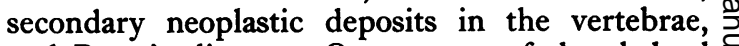
and Paget's disease. On account of the skeletal injury and paraplegia, the patient is often confined to bed for a long period.

No really satisfactory treatment has been evolved for the 'paraplegic bladder.' This partly because it is impossible to foretell how lon the paralyzed bladder will remain atonic before it develops automatic reflex emptying, and partly because urinary infection is almost inevitable. According to Thomson-Walker (1937), urinary infection was largely responsible for the 80 per cent. mortality amongst paraplegics in the first world war. Constant and prolonged attack against sepsis must, therefore, be maintained, chiefly by forcing fluids and administering urinary antiseptics such as potassium or sodium citrate, mandelic acid, hexamine and sulphonamides.

The most difficult problem is the drainage of the bladder during the paralytic phase. The available methods have been recently summarized by Dick (1952). Briefly they are :

I. Intermittent catheterization.

2. Indwelling catheter.

3. Indwelling catheter with tidal drainage.

4. Suprapubic cystotomy.

5. Manual compression.

6. Non-interference: retention with overflow.

Each of these methods has a place in individual $\frac{0}{D}$ patients, but the most universally applicable are $\stackrel{\oplus}{+}$ suprapubic cystotomy and tidal drainage. With the introduction of the less irritating Foley catheter, it is likely that tidal drainage through an 
indwelling catheter will become the method of choice.

\section{Prostatic Obstruction}

It is a common observation that the elderly man suddenly confined to bed is likely to develop acute retention of urine. Occasionally the passing of a catheter once or twice relieves the condition, and no further treatment is necessary. Usually, however, the retention is due to bladder neck obstruction caused by an adenomatous or a fibrous prostate. Operation is required in these patients to relieve the obstruction. The choice of operation depends on the pathology of the prostate and the condition of the patient, and is determined by normal urological practice.

\section{Senility}

The population is ageing, and the care of the old is becoming an increasingly important social and medical problem. Many old people, enfeebled in mind and body and stricken with chronic disease, become completely bedridden. Frequently they have little control over their normal bodily functions, and incontinence is common. A great deal can be done for these patients if they can be coaxed or cajoled out of bed, even if it is only a matter of lifting them on to a bedside commode (Nisbet, 1953). If they can be sufficiently reassured and rehabilitated to make their own way to the lavatory, they will be well on the way to being cured of their incontinence. Old men can sometimes be cured by the simple expedient of leaving a urine bottle constantly by the bedside, and others will respond to the assurance that a bedpan will never be asked for in vain. Other simple measures are reducing the fluid intake late in the day, frequent regular bedpan rounds, and offering the bedpan before as well as after meals. Incontinence is sometimes due to urinary infection and, in such instances, treatment of the infection will cure the incontinence.

There remains the group of hopelessly enfeebled, unco-operative, bedridden and totally incontinent patients. Something can be done, especially in males, by the use of incontinence appliances, such as rubber urinals strapped to the thighs. For completely hopeless immobile patients the Brocklehurst bed (Brocklehurst, I95 I) may be used; this consists essentially of a bed in which there is a hole cut in the mattress under the perineum through which urine and faeces may pass to a receptacle below. Some of these patients are not only incontinent but filthy, and to improve the nursing of these patients Arnott and Nisbet (1952) have recently designed a gown which prevents the patient's hands from coming in contact with the perineum.

\section{Summary}

I. The urological problems arising from prolonged recumbency are considered.

2. Of these the most important is decubitus calculus. Its aetiology, prevention and treatment are described in detail.

3. Reference is made to the management of the paraplegic bladder, retention of urine and senile incontinence.

I wish to record my thanks to Dr. F. Harwood Stevenson of the Royal National Orthopaedic Hospital and to Mr. M. F. Nicholls for their great help in the preparation of this article. I also wish to thank Mr. E. J. Nangle and the Institute of Orthopaedics for permission to use Figs. 2 and 3 and Messrs. Blackwell Scientific Publications for the loan of the blocks.

\section{BIBLIOGRAPHY}

ALBRIGHT, F., as REIFENSTEIN, E. C. (1948), 'The Parathyroid 'Glands and Metabolic Bone Disease,' London, Balliere, Tindall \& Cox.

ARNOTT, A., and NISBET, N. H. (1952), Lancet, ii, 1206.

BROCKLEHURST, J. C. (I95I), 'Incontinence in Old People', Edinburgh.

CRAIG, W. MCK., and BARR, J. S. (1947), f. Internat. Coll. Surg., I0, 18.

DEITRICK, J. E., WHEDON, G. D., SHORR, E., and BARR,

D. P. (1945), ' Conference on Metabolic Aspects of Convalescence, Transactions of 9th Meeting,' J. Macy Foundation, p. 68.

DICK, T. B. S. (1952), Brit. F. Utology, 24 (2), ror.

HOWARD, J. E. (1945), F. Amer. Med. Ass., 129, 159.

JOELSON, J. J. (1945), Ibid., 129, 156.

KIMBROUGH, J. C., DENSLOW, J. C., and WORGAN, D. K. (1950), Ibil., 142, 787.

Lancet (1953), 'Ánnotation,' I, 332.

MCCUSKEY, JOHN F. (1950), f. Amer. Med. Ass., 142, 789. NANGLE, E. J. (195I), 'Instrum ents and Apparatus in Orthopaedic Surgery,' Oxford, Blackwell Scientific Publications.

NISBET, N. H. (1953), Lancet, 1, 184.

RICHES, E. W. (1943), Brit. F. Surg., 31, 135.

SATTERTHWAITE, R. W. (1947), Paper read before the American College of Surgeons, Section on Urology, New York.

SHORR, EPHRAIM, and CARTER, ANNE C. (1950), F. Amer. Med. Ass., 144 (18), 1549.

SISSONS, H. A. (1952), F. Bone Eீ foint Surgery, 34-B (2), 256. STEVENSON, F. HARWOJD (1952), Ibid., 34-B (2), 256; (1953), Personal communication.

SWARTZ, D., and TAYLOR, J. R. (1950), Canad. M. A. F., 63, 559. THOMSON-WALKER, SIR J. (1937), Proc. Roy. Soc. Med., 30,
1233. 